\title{
Analysis of Strain and Intermixing in Single-Layer Ge/Si Quantum Dots Using Polarized Raman Spectroscopy
}

Anna Baranov

Vavilov State Optical Institute, St. Petersburgh

A. V. Federov

Vavilov State Optical Institute, St. Petersburgh

Tatiana Perova

Trinity College Dublin

See next page for additional authors

Follow this and additional works at: https://arrow.tudublin.ie/engscheceart

Part of the Electrical and Electronics Commons

\section{Recommended Citation}

Baranov, A.V., Fedorov, A.V., Persova, T.S., Moore, R.A., Yam, V., Bouchier, D., Le Thanh, V. and Kevin Berwick : Analysis of Strain and Intermixing in Single-Layer Ge/Si Quantum Dots Using Polarized Raman Spectroscopy. Physics Review B., Vol.73, 7, 2006. DOI:10.1103/PhysRevB.73.075322

This Article is brought to you for free and open access by the School of Electrical and Electronic Engineering at ARROW@TU Dublin. It has been accepted for inclusion in Articles by an authorized administrator of ARROW@TU

Dublin. For more information, please contact

arrow.admin@tudublin.ie, aisling.coyne@tudublin.ie, gerard.connolly@tudublin.ie.

Funder: HEA, DIT

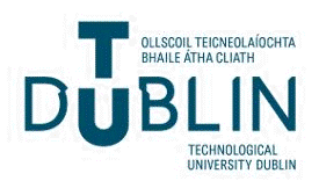




\section{Authors}

Anna Baranov, A. V. Federov, Tatiana Perova, R. A. Moore, V. Yam, D. Bouchier, V. Le Thanh, and Kevin Berwick 


\title{
Analysis of strain and intermixing in single-layer Ge/Si quantum dots using polarized Raman spectroscopy
}

\author{
A. V. Baranov and A. V. Fedorov \\ Vavilov State Optical Institute, 199034, St.-Petersburg, Russia \\ T. S. Perova* and R. A. Moore \\ Department of Electronic and Electrical Engineering, University of Dublin, Trinity College, Dublin 2, Ireland \\ V. Yam and D. Bouchier \\ Institut d'Electronique Fondamentale, UMR CNRS 8622, Bât. 220, Université Paris-Sud, 91405 Orsay, France \\ V. Le Thanh \\ Centre de Recherche sur les Mécanismes de la Croissance Cristalline (CRMC2-CNRS), Campus de Luminy, Case 913, \\ 13288 Marseille cedex 9, France \\ K. Berwick \\ Department of Electronic and Communications Engineering, Dublin Institute of Technology, Dublin 8, Ireland
}

(Received 26 August 2005; revised manuscript received 23 November 2005; published 17 February 2006)

\begin{abstract}
The built-in strain and composition of as-grown and $\mathrm{Si}$-capped single layers of $\mathrm{Ge} / \mathrm{Si}$ dots grown at various temperatures $\left(460-800{ }^{\circ} \mathrm{C}\right.$ ) are studied by a comparative analysis of the Ge-Ge and $\mathrm{Si}-\mathrm{Ge}$ modes in the polarized Raman spectra of the dots. A pronounced reduction of the strain and Ge content in the dots after deposition of the cap layer at low temperatures is observed, indicating that strain-induced Si diffusion from the cap layer is occurring. For large dots grown at $700-800{ }^{\circ} \mathrm{C}$ the observations are in agreement with a model of the $\mathrm{Ge} / \mathrm{Si}$ dot consisting of a Si-rich boundary region and a Ge-rich core.
\end{abstract}

DOI: 10.1103/PhysRevB.73.075322

PACS number(s): 81.07.Ta, 78.30.Fs, 78.67.Hc, 81.15.Gh

\section{INTRODUCTION}

In recent years, a considerable amount of work has been devoted to the study of semiconductor self-assembled quantum dots (QD's) which can be successfully grown from III-V, II-VI, and Group-IV lattice-mismatched semiconductors using a Stranski-Krastanov growth technique. ${ }^{1} \mathrm{Ge} / \mathrm{Si}$ selfassembled QD's are of particular interest because of their compatibility with Si-based electronics. The growth of highquality, Ge/Si, self-assembled QD's can be achieved by molecular beam epitaxy or chemical vapor deposition (see review in Ref. 2 and references therein).

The presence of strain and the specific chemical composition of semiconductor quantum dots has an enormous influence on their optical and electrical properties. Intense and, in some cases, anisotropic strain is essential for the growth of self-assembled and strain-induced quantum dots. ${ }^{1,3}$ Strain results in a reconstruction of the electronic and vibrational structure of the quantum dots comparable to that induced by the quantum confinement effect. The interdiffusion of atoms surrounding the dot into the crystal lattice of the dot, the intermixing effect, is a crucial step in the formation of the nanostructure. This intermixing effect influences the shape and depth of the potential wells for electronic excitations, the elastic coefficients of the materials, and therefore their phonon spectra. Because of the small size of the dots, the change in composition caused by intermixing may be very large. As an example, the Si content in germanium dots embedded in a $\mathrm{Si}$ structure can increase by up to $70 \%$ as a result of intermixing. ${ }^{4}$ This raises the possibility of utilizing strain and composition effects in order to manipulate quantum dot parameters or to synthezise novel quantum dot structures. This has already been done for III-V quantum dots grown by droplet epitaxy. ${ }^{5}$ Knowledge of these parameters is of crucial importance for future optoelectronic applications of quantum dot nanostructures.

$\mathrm{Ge} / \mathrm{Si}$ quantum dot heterostructures are of special interest for the study of intermixing and strain effects. Indeed, in many cases in these heterostructures, the quantum dot material is a binary alloy $\mathrm{Ge}_{x} \mathrm{Si}_{(1-x)}$ with $0<x<1$. Strain is also unavoidable due to the large Ge-Si lattice mismatch. Despite its great importance, a comprehensive understanding of the combined effects of strain and intermixing in $\mathrm{Ge}-\mathrm{Si}$ dots has yet to be realized. The details of the intermixing process in $\mathrm{Ge} / \mathrm{Si}$ dots remain unclear. A random distribution of $\mathrm{Si}$ atoms in Ge dots has been predicted theoretically in Ref. 6. On the other hand, a highly anisotropic lateral Ge profile was found by a selective etching technique in uncapped $\mathrm{Ge} / \mathrm{Si}$ pyramids and explained by a model of intermixing caused by surface diffusion. ${ }^{7}$ X-ray diffraction (XRD) data on buried ${ }^{8}$ and uncapped ${ }^{9} \mathrm{Ge} / \mathrm{Si}$ dots, selective etching of stacked dot layers, ${ }^{10}$ and micro-Raman data on $\mathrm{Ge} / \mathrm{Si} \operatorname{dots}^{4}$ and thinlayer heterostructures exhibit significant $z$ anisotropy of the $\mathrm{Ge}$ content due to intermixing. Overgrowth of dots by a $\mathrm{Si}$ layer is usually required in these structures. This overgrowth generates additional intermixing and relaxation in the dots. For this reason the effect of the overgrowth parameters on the strain and Ge composition profile in single layer $\mathrm{Ge} / \mathrm{Si}$ 
dots has been studied by XRD (Refs. 8 and 11) and photoluminescence (Ref. 12) techniques.

Raman spectroscopy, a rapid, sensitive, contactless, and nondestructive analytical method, is widely used for the characterization of $\mathrm{Ge} / \mathrm{Si}$ nanostructures. Indeed, the position, intensity, and width of Raman lines due to the local $\mathrm{Ge}-\mathrm{Ge}, \mathrm{Ge}-\mathrm{Si}$, and $\mathrm{Si}-\mathrm{Si}$ modes of the $\mathrm{Ge} / \mathrm{Si}$ alloy enable one to obtain information on the composition, strain, and confinement within the Ge-Si nanostructures. ${ }^{3,4,13-15}$ However, there is difficulty regarding the analysis of Raman spectra of $\mathrm{Ge} / \mathrm{Si}$ dots grown on $\mathrm{Si}$ substrates due to overlapping of the $\mathrm{Ge}-\mathrm{Si}$ and $\mathrm{Ge}-\mathrm{Ge}$ modes of $\mathrm{Ge} / \mathrm{Si}$ with the twophonon spectrum [transverse acoustical (TA) modes] of the Si substrate, or spacers, at $\sim 435$ and $\sim 302 \mathrm{~cm}^{-1}$ (see discussion in Refs. 16-18). Since the two-phonon spectrum of $\mathrm{Si}$ is strongly polarized, ${ }^{19}$ a suggestion has been made to take polarized Raman measurements of Ge/Si nanostructures in a configuration which allows suppression of the contribution of the silicon acoustic phonons to the Raman spectra in the region $\sim 200-460 \mathrm{~cm}^{-1}$ (Refs. 17 and 19-21). This approach has recently been successfully applied for studying strain and composition in a $\mathrm{Ge} / \mathrm{Si}$ multilayer dot heterostructure with a Ge content of up to $70 \%$ (Ref. 4).

Analysis of Raman spectra is simplified for dots with a relatively low $\mathrm{Si}$ content, ${ }^{19}$ because the Raman cross section of Ge is 1000 times greater that that of Si. Also, it is easier to take these measurements from multilayer dot structures, $,, 20,22$ where the signal from a large number of dots is analyzed. Considerable experimental difficulties arise when attempting to take measurements from a single $\mathrm{Ge} / \mathrm{Si}$ dot layer with a large Si content whose Raman spectra are dominated by the two-phonon peaks of the silicon substrate. Nevertheless, these measurements are of great importance because the Raman spectra of multilayer structures provide stress values and intermixing averaged over a number of dot layers due to the relatively large penetration depth of the probe beam into the sample. ${ }^{4}$ However, to the best of our knowledge, Raman studies have not been performed to date in order to determine the composition profile and the strain state inside single-layer $\mathrm{Si} / \mathrm{Ge}$ dots with a large $\mathrm{Si}$ content.

This paper reports polarized micro-Raman studies of the strain and atomic intermixing effect in single-layer $\mathrm{Ge} / \mathrm{Si}$ dots grown on $\mathrm{Si}(001)$ surfaces at a variety of temperatures for both as-grown dot layers and dot layers under a Si cap layer.

\section{EXPERIMENT}

Ge dots were grown using an ultrahigh-vacuum chemical vapor deposition (UHV CVD) system. Pure $\mathrm{SiH}_{4}$ and hydrogen-diluted $(10 \%) \mathrm{GeH}_{4}$ were used as gas sources. Transmission electron microscopy (TEM) measurements were performed on sample cross sections using a $400-\mathrm{kV}$ microscope. Details of the experimental setup and the growth conditions have been reported elsewhere. ${ }^{23}$

A set of samples, grown at various temperatures, each consisting of a single-dot layer, was fabricated as follows. The temperature of the Ge layer growth was varied from 460 to $800{ }^{\circ} \mathrm{C}$. At each of these temperatures a pair of samples, one with and one without a $\mathrm{Si}$ cap layer, was grown. The Ge dots were capped by $\mathrm{Si}$ at the same deposition temperature that was used for Ge growth. The size and shape of the as-grown samples were characterized by crosssectional high-resolution TEM and atomic force microscopy (AFM) techniques. Depending on the growth temperature, the Ge dots formed have different shapes, sizes, and areal density. The hut- and pyramid-shaped $\mathrm{Ge} / \mathrm{Si}$ dots prepared were found to be highly oriented along the crystallographic axes of the Si substrate. ${ }^{24}$ The growth conditions and properties of these samples are summarized in Table I. Typical AFM images of samples studied are shown in Figs. 1(a)-1(c).

Raman spectra were registered in backscattering geometry using a RENISHAW 1000 micro-Raman system equipped with a Leica microscope. To prevent sample heating the power density was kept below $10^{5} \mathrm{~W} / \mathrm{cm}^{2}$. Measurements were performed at room temperature with the $514.5-\mathrm{nm}$ line from an argon ion laser. A spot size of about $1 \mu \mathrm{m}$ was used throughout the study. An 1800-lines/mm grating was used for all measurements, corresponding to a spectral resolution of $\sim 2 \mathrm{~cm}^{-1}$ per 3 pixels.

Polarized Raman measurements were performed in backscattering geometry with a polarization configuration chosen according to the Raman selection rules to allow the signals from the Ge dot layer to be distinguished from those from the Si substrate. The sample position, crystallographic axes of the $\mathrm{Si}$ wafer, and polarizations of the incident and scattered light are shown in Fig. 1(d). Note that strain-induced LO-TO frequency splitting of the Ge-Ge mode, which is often utilized for strain measurements in Ge/Si QD's, ${ }^{19,20,22}$ cannot be used for single-dot layers. Therefore, Raman spectra were obtained in VH or [001(100, 010)00-1] (Porto's notation) configurations [Fig. 1(d)], where scattering by the 2TA Si mode (peak at $\sim 302 \mathrm{~cm}^{-1}$ ) is forbidden but scattering by the LO-like Si and Ge modes is allowed. All spectra were registered using the same accumulation time of $60 \mathrm{~s}$. Forty accumulations were taken for each Raman spectrum measurement. In order to define the position of the phonon lines with a higher accuracy, the Raman bands were fitted with a Voigt function where the Gaussian contribution is a combination of the apparatus function and inhomogeneous broadening of the Raman lines because of the nonuniform dot composition.

\section{RESULTS AND DISCUSSION}

A set of representative Raman spectra (thick lines) measured in $V H$ geometry in the region $250-500 \mathrm{~cm}^{-1}$ is presented in Fig. 2(a) for samples grown at a temperature of $460{ }^{\circ} \mathrm{C}$ (1, as-grown; 2, with 20-nm Si cap layer) and $550{ }^{\circ} \mathrm{C}$ (3, with 20-nm Si cap layer). Raman spectra of the corresponding Si substrates, as reference spectra, obtained under the same conditions are also presented for comparison in Fig. 2(a) as thin lines. Prominent differences are clearly discernible between the sample and reference spectra in the region of interest. Although the 2TA band is observed at $\sim 300 \mathrm{~cm}^{-1}$ in both the sample spectra and the reference ones in the $V H$ geometry, the Ge-Ge peak with an intensity suffi- 
TABLE I. Growth conditions and parameters of samples with a single layer of $\mathrm{Ge} / \mathrm{Si}$ dots.

\begin{tabular}{ccclccc}
\hline \hline $\begin{array}{c}\text { Growth } \\
\begin{array}{c}\text { temperature } \\
\left({ }^{\circ} \mathrm{C}\right)\end{array}\end{array}$ & $\begin{array}{c}\text { Si cap } \\
\text { thickness } \\
(\mathrm{nm})\end{array}$ & $\begin{array}{c}\text { Dots: } \\
\text { base/height } \\
(\mathrm{nm})\end{array}$ & $\begin{array}{c}\text { Shape of } \\
\text { dots }\end{array}$ & $\begin{array}{c}\text { Areal } \\
\text { density } \\
\left(\mu \mathrm{m}^{-2}\right)\end{array}$ & $\begin{array}{c}\text { Ge content } \\
x\end{array}$ & $\begin{array}{c}\text { Strain } \\
\varepsilon\end{array}$ \\
\hline 800 & 0 & $220 / 21$ & $\begin{array}{l}\text { Pyramids } \\
\text { 270/40 }\end{array}$ & $\begin{array}{l}\text { Domes } \\
22.3\end{array}$ & $0.36 \pm 0.04$ & $-0.012 \pm 0.003$ \\
800 & 70 & $270 / 21$ & Pyramids & 2.3 & $0.34 \pm 0.05$ & $-0.011 \pm 0.003$ \\
& & $100 / 12$ & Pomes & & & \\
700 & 0 & $110 / 22$ & Domes & 10 & $0.34 \pm 0.05$ & $-0.014 \pm 0.003$ \\
& & $100 / 12$ & Pyramids & 10 & $0.32 \pm 0.05$ & $-0.013 \pm 0.003$ \\
700 & 60 & $110 / 22$ & Domes & & & \\
& & $100 / 15$ & Domes & 14 & $0.40 \pm 0.04$ & $-0.018 \pm 0.002$ \\
600 & 0 & $100 / 15$ & Domes & 14 & $0.34 \pm 0.04$ & $-0.014 \pm 0.002$ \\
600 & 46 & $95 / 14$ & Domes & 30 & $0.52 \pm 0.04$ & $-0.022 \pm 0.002$ \\
550 & 0 & $95 / 14$ & Domes & 30 & $0.40 \pm 0.04$ & $-0.017 \pm 0.002$ \\
550 & 22 & $50 / 5$ & Hut clusters & 150 & $0.65 \pm 0.07$ & $-0.025 \pm 0.003$ \\
525 & 0 & $50 / 5$ & Hut clusters & 150 & $0.47 \pm 0.04$ & $-0.018 \pm 0.002$ \\
525 & 20 & $48 / 5$ & Hut clusters & 100 & $0.85 \pm 0.10$ & $-0.028 \pm 0.004$ \\
460 & 0 & $48 / 5$ & Hut clusters & 100 & $0.50 \pm 0.04$ & $-0.020 \pm 0.002$ \\
460 & 20 & & & & & \\
\hline \hline
\end{tabular}

cient for analysis appears as a low-energy shoulder of the $\mathrm{Si}$ 2TA peak in the sample spectrum. Importantly, the high degree of orientation of the hut- and pyramid-shaped Ge dots on the $\mathrm{Si}$ substrate in the samples studied ${ }^{24}$ results in the highest value of intensity in the LO-phonon-like Ge-Ge peak in the $V H$ polarization configuration.

The characteristic Raman spectrum of the Ge/Si dots $\left(I_{D}\right)$ was obtained by taking the difference between the Raman spectra of the sample $\left(I_{S}\right)$ and the reference Si wafer $\left(I_{S i}\right)$ measured in the $V H$ geometry:

$$
I_{D}=I_{S}-F I_{S i},
$$

where $F$ is a scaling factor, obtained by taking the ratio of the LO-phonon bands of the Si substrate at $520 \mathrm{~cm}^{-1}$ in the Raman spectrum of the sample and the reference $\mathrm{Si}$ wafer, $F=\left(I_{S} / I_{S i}\right)_{520}$. Using this approach, the contribution of the $\mathrm{Si}$ substrate to the Raman spectrum of the sample can be taken into account. ${ }^{4}$ The contribution of the Ge wetting layer to the spectra is expected to be negligible. ${ }^{4,19}$

In order to compare the intensities of the Raman signals from different samples, the spectra were normalized to the intensity of the Si substrate peak at $520 \mathrm{~cm}^{-1}$ and the total volume of the dots illuminated by the incident light. A representative set of dot Raman spectra obtained in this way is shown in Fig. 2(b) for samples grown at different temperatures. Results are shown for both as-grown samples (thin line) and samples capped by a Si layer (thick line). Three features at frequencies of $\sim 300, \sim 420$, and $\sim 450 \mathrm{~cm}^{-1}$ are seen in the Raman spectra [Fig. 2(b)]. Assignment of these bands is well established: ${ }^{13,25}$ the first and second peaks belong to the $\mathrm{Ge}-\mathrm{Ge}$ and $\mathrm{Si}-\mathrm{Ge}$ modes, respectively, while the third feature at $440-470 \mathrm{~cm}^{-1}$ is attributed to unresolved lines of localized $\mathrm{Si}-\mathrm{Si}$ vibrations in the neighborhood of different numbers of Ge atoms. As can be seen from Fig. 2(b), the Raman spectra differ from each other depending on the temperature of the dot layer growth and whether a Si cap layer is present. The intensities of the $\mathrm{Ge}-\mathrm{Ge}$ and $\mathrm{Si}-\mathrm{Ge}$ bands in the Raman spectra of samples containing a single layer of dots were sufficient for analysis with $\sim 5 \%$ uncertainty in the integrated intensities. The intensities of the $\mathrm{Si}-\mathrm{Ge}$ band for the dot layers grown at 460 and $525^{\circ} \mathrm{C}$ with-
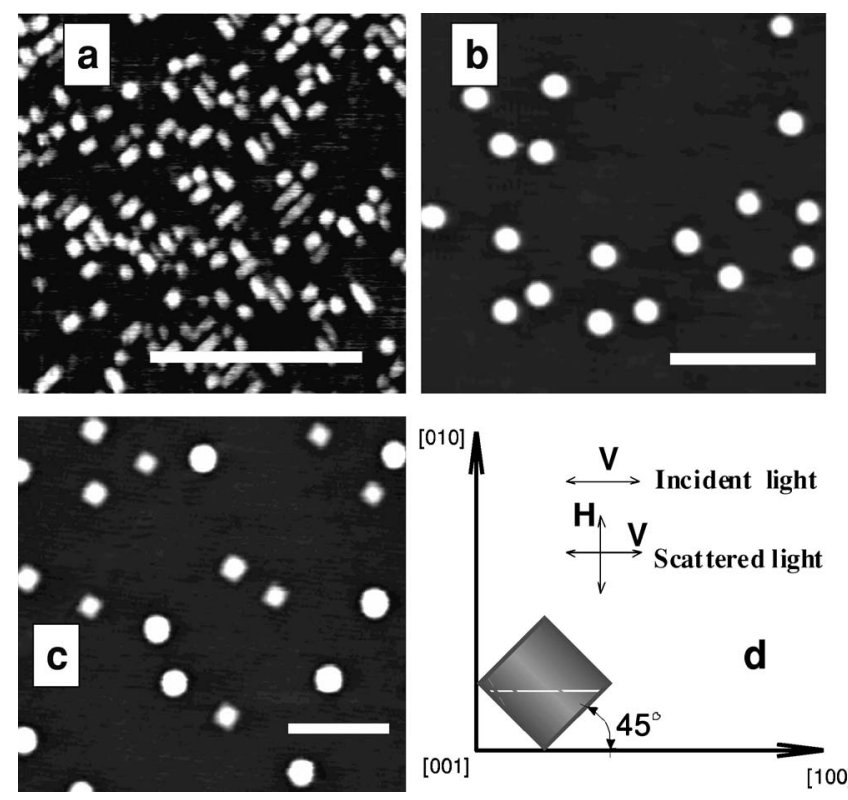

FIG. 1. AFM image of $\mathrm{Ge} / \mathrm{Si}(001)$ dots grown at different temperatures: (a) $525^{\circ} \mathrm{C}$, (b) $600{ }^{\circ} \mathrm{C}$, and (c) $800{ }^{\circ} \mathrm{C}$; scale bars of $0.25,0.5$, and $1.0 \mu \mathrm{m}$, respectively, are shown. (d) Schematic of electric vector orientation in incident and scattered channels during polarized Raman measurements. 


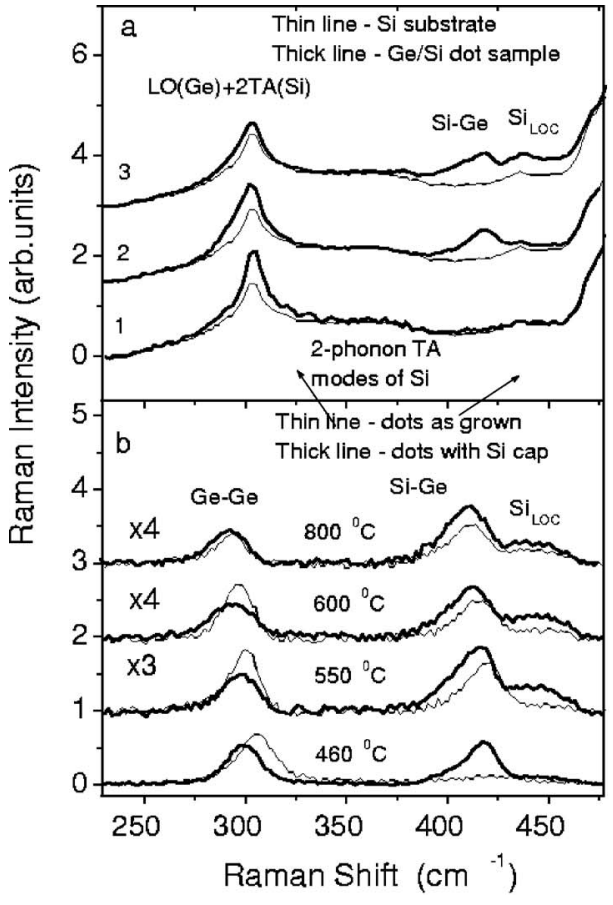

out a silicon cap layer were measured with uncertainties of $10 \%$ and $8 \%$, respectively. However, due to the very large intensity of the Si substrate LO-phonon line at $520 \mathrm{~cm}^{-1}$ in the spectra of the samples, we were not able to reliably distinguish the $\mathrm{Si}-\mathrm{Si}$ line originating from the $\mathrm{Ge} / \mathrm{Si}$ dots which is usually utilized for analysis of the strain and composition within the dots. ${ }^{19,22,25,26}$ Therefore, for heterostructures with a single layer of $\mathrm{Ge} / \mathrm{Si}$ dots we are restricted to examination of the positions and the integrated intensities of the $\mathrm{Ge}-\mathrm{Ge}$ and Si-Ge Raman bands only.

The Raman spectra of the uncapped QD layers grown at $460{ }^{\circ} \mathrm{C}$ [see Fig. 2(b)] and $525^{\circ} \mathrm{C}$ show a very weak Si-Ge peak and strong Ge-Ge peak located at $\sim 307-303 \mathrm{~cm}^{-1}$. This demonstrates that the Ge-Ge-mode frequencies exceed that for bulk Ge $\left[300.8 \mathrm{~cm}^{-1}\right.$ (Ref. 27)], indicating the presence of compressive strain inside the dots and a high $\mathrm{Ge}$ content within the dots. The intensities of the Ge-Ge peaks in the spectra of the other samples are comparable with those of the Si-Ge peaks, suggesting a Ge content of $40 \%-60 \%$ in the Ge/Si dots. ${ }^{19,22,26,28}$ Figures 2(c) and 2(d) present the temperature dependences of the $\mathrm{Si}-\mathrm{Ge}$ and $\mathrm{Ge}-\mathrm{Ge}$ peak positions for $\mathrm{Si} / \mathrm{Ge}$ dots, for both as-grown and $\mathrm{Si}$ capped layers.

The ratio of the integrated intensities of the Ge-Ge and $\mathrm{Si}-\mathrm{Ge}$ Raman peaks, $I_{\mathrm{Ge}-\mathrm{Ge}} / I_{\mathrm{Si}-\mathrm{Ge}}=B x / 2(1-x)$, can be used for determining the $\mathrm{Ge}$ content in $\mathrm{Ge} / \mathrm{Si}$ alloys and nanostructures. ${ }^{4,19,26}$ Here $x$ is the Ge content and $B$ is a constant depending on the experimental conditions. The validity of this equation was initially checked for polarized Raman measurements in our experimental setup for a number of thin SiGe layers with known Ge content, situated between Si epitaxial layers. In this way, we determined a coefficient $B$ of 1.5 for our experiments. The values of $x$ for the dots studied are listed in Table I and shown in Fig. 3(a) for both as-grown and Si-capped dot layers. The errors are calculated using the standard deviations of the values for the integrated intensities of the Ge-Ge and Si-Ge modes.
FIG. 2. (a) Raman spectra collected in $\mathrm{VH}$ polarization of $\mathrm{Si}$ substrate (thin line) and samples grown at $460{ }^{\circ} \mathrm{C}(1$, without $\mathrm{Si}$ cap layer, and 2, with 20-nm $\mathrm{Si}$ cap layer), and (3) at $550{ }^{\circ} \mathrm{C}$ with 20-nm Si cap layer. (b) Differential Raman spectra for single-layer $\mathrm{Ge} / \mathrm{Si}$ dots grown at different temperatures with (thick line) and without (thin line) a Si cap layer. The dependence of the peak position of (c) Ge-Ge and (d) Si-Ge phonon modes vs growth temperature for as-grown $(\square)$ and coated with Si cap layer $(\mathbf{\square}) \mathrm{Ge} / \mathrm{Si}$ dots.
In general, a shift in the Ge-Ge peak within the $\mathrm{Ge} / \mathrm{Si}$ dots from the Ge bulk value can be attributed to (1) a confinement effect, (2) an intermixing effect, and (3) stress within the dots. Confinement tends to shift the Ge-Ge phonon peak downwards as the size of the dots reduces below 2-3 nm (Refs. 29 and 30). In this study, the size of the $\mathrm{Ge} / \mathrm{Si}$ dots is too large to expect a substantial confinement effect. Normally, intermixing decreases the Ge phonon frequency when compared with that for bulk germanium, while

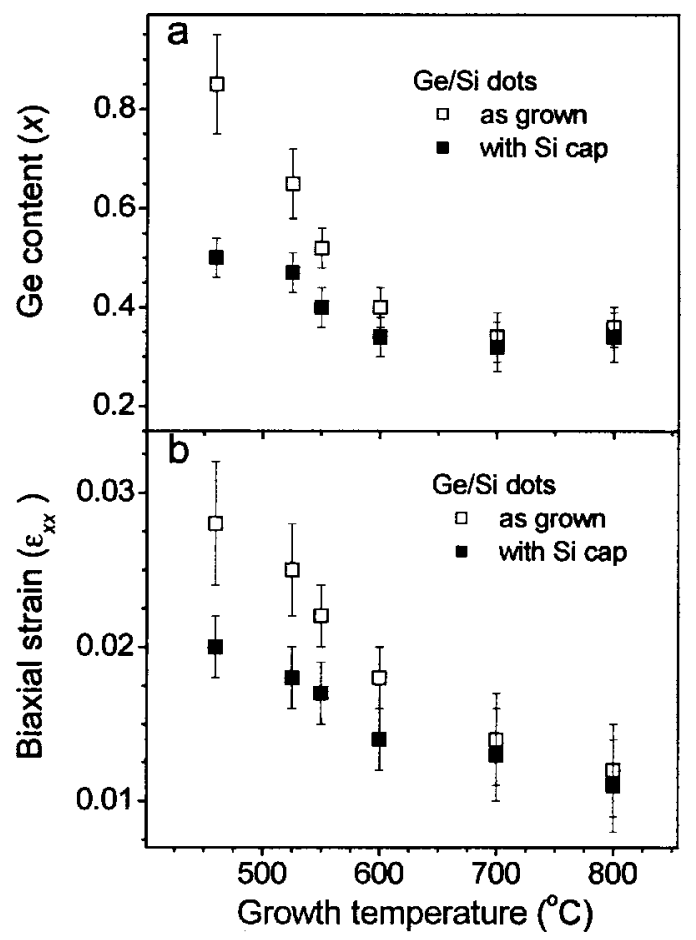

FIG. 3. Dependence of (a) Ge content $x$ and (b) biaxial strain $\varepsilon$ on growth temperature for $\mathrm{Ge} / \mathrm{Si}$ dots. 
compressive biaxial stress results in an upward frequency shift of the Ge-Ge and Si-Ge modes relative to those in a relaxed $\mathrm{SiGe}$ alloy. The Raman peak positions in $\mathrm{Ge} / \mathrm{Si}$ dot systems are determined by the interplay between these two effects.

To a first-order approximation, we will only consider the biaxial strain in a $\mathrm{Si} / \mathrm{Ge}$ layer structure, since the height-tobase ratio is small for all dots studied. The biaxial strain in the dot can be found from the Ge-Ge and Si-Ge peak positions using a model of biaxial strain in the (001) plane and the cusplike behavior of the $\mathrm{Si}-\mathrm{Ge}$ mode in relaxed $\mathrm{Ge} / \mathrm{Si}$ alloys. ${ }^{19,25,26}$ In order to extract information on stress and intermixing in the $\mathrm{Ge} / \mathrm{Si}$ dots from the shift of the Ge-Ge and Si-Ge Raman bands, we utilize an approach developed in Refs. 19 and 26. Based on the $x$ values obtained from the ratio of the integrated intensities of the $\mathrm{Ge}-\mathrm{Ge}$ and $\mathrm{Si}-\mathrm{Ge}$ peaks, the value of the strain can be estimated by using empirical expressions both for $\mathrm{Si}-\mathrm{Ge}\left(\omega_{\mathrm{Si}-\mathrm{Ge}}\right)$ and $\mathrm{Ge}-\mathrm{Ge}$ $\left(\omega_{\mathrm{Ge}-\mathrm{Ge}}\right)$ peak positions. These expressions, viz.,

$$
\begin{gathered}
\omega_{\mathrm{Si}-\mathrm{Ge}}\left(\mathrm{cm}^{-1}\right)=400.5+14.2 x-575 \varepsilon_{x x}, \\
\omega_{\mathrm{Ge}-\mathrm{Ge}}\left(\mathrm{cm}^{-1}\right)=282.5+16 x-384 \varepsilon_{x x},
\end{gathered}
$$

were obtained and verified for $\mathrm{Ge}_{x} \mathrm{Si}_{1-x}$ alloys with a $\mathrm{Ge}$ content of $x<0.5$ (Ref. 26). Here $\varepsilon_{x x}$ is the biaxial strain in the (001) plane, which is directly related to the biaxial stress $\sigma$. The arithmetic average values of $\varepsilon_{x x}$ calculated separately from the $\omega_{\mathrm{Si}-\mathrm{Ge}}$ and $\omega_{\mathrm{Ge}-\mathrm{Ge}}$ data for dots with $x \leqslant 0.5$ are listed in Table I and shown in Fig. 3(b) as a function of the growth temperature for both as-grown and Si-capped dot layers. For the uncapped samples grown at 460, 525, and $550{ }^{\circ} \mathrm{C}$, where $x>0.5$, the $\varepsilon_{x x}$ values were calculated by using the dependence of $\omega_{\mathrm{Ge}-\mathrm{Ge}}$ on strain, given by

$$
\omega_{\mathrm{Ge}-\mathrm{Ge}}\left(\mathrm{cm}^{-1}\right)=\omega_{\mathrm{Ge}-\mathrm{Ge}}^{0}+b_{\mathrm{Ge}-\mathrm{Ge}} \varepsilon_{x x},
$$

where $\omega_{\mathrm{Ge}-\mathrm{Ge}}^{0}$, the frequency of the Ge-Ge mode in unstrained $\mathrm{Si} / \mathrm{Ge}$ alloys, is taken from Ref. 25 and $b_{\mathrm{Ge}-\mathrm{Ge}}$ is the phonon strain-shift coefficient of $-400 \mathrm{~cm}^{-1}$ (Ref. 19). As shown in Ref. 19, this expression describes well the biaxial strain in $\mathrm{Ge} / \mathrm{Si}$ dots with a high $\mathrm{Ge}$ content. The biaxial strain thus calculated is also presented in Table I, and shown in Fig. 3(b) versus growth temperature. Allowing for errors, the ratio of the strain and Ge content values for our samples is close to -0.042 , characteristic of pseudomorphic, biaxially strained $\mathrm{SiGe}$ layers on a $\mathrm{Si}$ substrate.

For a single layer of dots, intermixing may occur at the dot/substrate interface for as-grown dots and additionally at the interface between the dots and cap layer for samples capped by silicon. Intermixing may be caused by thermoinduced atomic diffusion and also by the strain field distributed over the dot surface. The uncapped dots grown at the relatively low temperatures of 460 and $525^{\circ} \mathrm{C}$ possess a Ge content $x$ of 0.85 and 0.65 and compressive strains of -0.028 and -0.025 , respectively. These hut-shaped dots have similar sizes, and the reduction of $x$ and $\varepsilon_{x x}$ is most likely to have resulted from temperature-induced intermixing and strain relaxation at the dot/substrate interface during dot growth.

Surprisingly, deposition of a 20-nm Si cap layer results in a dramatic reduction of the Ge content in these samples to
0.5 and 0.47 coupled with an elastic strain relaxation to -0.02 and -0.018 . This suggests that the migration process of $\mathrm{Si}$ atoms from the cap layer into the dots becomes more efficient than migration from the $\mathrm{Si}$ substrate. However, given that intermixing governed by the surface interdiffusion would be expected to be proportional to the $\mathrm{Ge}-\mathrm{Si}$ interface area, the increasing $\mathrm{Si}$ content, especially in the sample grown at $460{ }^{\circ} \mathrm{C}$, cannot be explained by a simple increase of the Ge-Si interface surface due to capping. We believe that, for relatively small dots, strain-induced Si diffusion from the cap layer contributes significantly to a reduction of the Ge content and strain relaxation in the capped dots. This is supported by the fact that, in the region $460-600{ }^{\circ} \mathrm{C}$, the uncapped dots demonstrate stronger dependences of $x$ and $\varepsilon_{x x}$ on temperature than the dots capped by the silicon layer (Fig. 3).

In general, the Ge content and strain gradually reduce as the growth temperature increases. Simultaneously the differential in the Ge content as well as in the strain value between as-grown and capped dots decreases and becomes negligible at 700 and $800{ }^{\circ} \mathrm{C}$, indicating a reduction of the cap layer contribution to intermixing and strain relaxation at these temperatures. The behavior of the temperature dependences of intermixing for as-grown and capped dots derived from our Raman data agrees qualitatively with data obtained in photoluminescence experiments for analogous single-layer $\mathrm{Ge} / \mathrm{Si}$ dots ${ }^{12}$ where the increased contribution of Si intermixing during capping with a reduction of the capping temperature has been observed. The XRD investigations of the Ge content for SiGe domelike dots layer grown at $630^{\circ} \mathrm{C}$ and capped by a Si layer at capping temperatures of 460 , 540 , and $630{ }^{\circ} \mathrm{C}$ (Ref. 11) showed that the influence of the cap layer on the composition and strain within the dots reduces with a reduction of the capping temperature. However, this finding does not contradict our observation and can be explained by the fact that free-standing dots grown at $630{ }^{\circ} \mathrm{C}$ have already intermixed and relaxed substantially.

It should be noted that at $800{ }^{\circ} \mathrm{C}$ both as-grown and capped dots show an upward trend in Ge content although the strain continues to decrease. This is most likely because the size of the dots grown at $800{ }^{\circ} \mathrm{C}$ is much larger than the sizes of the dots grown at lower temperatures (see Table I). In addition, it is believed that intermixing mainly occurs at the boundary regions of the large dots; i.e., the dots consist of a Ge-rich core and a Si-rich shell generating a gradient in the Si concentration. Although the diffusion coefficient increases rapidly at growth temperatures from 700 to $800{ }^{\circ} \mathrm{C}$ (Ref. 20), the anticipated increase in dot size would be expected to lead to a relative increase in the contribution from the Ge-rich core to the Raman signal, as compared with that from the Si-rich shell. The existence of a nonuniform composition is supported by the fact that the peak width of the Ge-Ge mode of about $20-22 \mathrm{~cm}^{-1}$ was found for the $\mathrm{Ge} / \mathrm{Si}$ dot studied. This is broader than that of $\sim 15 \mathrm{~cm}^{-1}$ reported for $\mathrm{Si} / \mathrm{Ge}$ superlatices and $\mathrm{SiGe}$ alloys. ${ }^{31}$

\section{CONCLUSION}

In conclusion, we have demonstrated that polarized micro-Raman spectroscopy can be used for the study of the 
evolution of composition and biaxial strain even in single layers of $\mathrm{Ge} / \mathrm{Si}$ dots. The dependences of these parameters on the dot growth temperature for both as-grown layers and layers covered by a thin Si cap layer are presented. We found that the temperature dependences of the Si capping effect on the biaxial strain and intermixing in single layers of $\mathrm{Ge} / \mathrm{Si}$ dots grown on $\mathrm{Si}$ (001) surfaces correspond qualitatively to those determined in XRD and photoluminescence experiments performed on analogous $\mathrm{Ge} / \mathrm{Si}$ structures. ${ }^{11,12}$ The $\mathrm{Ge}$ content and biaxial strain dependences on the growth temperature in capped and uncapped $\mathrm{Ge} / \mathrm{Si}$ dot single layers also qualitatively agree with those obtained by Raman spectroscopy of $\mathrm{Ge} / \mathrm{Si}$ dot superlattices. ${ }^{19,22}$ It has been found that, at low temperatures, the deposition of the Si cap layer strongly affects intermixing which causes elastic strain relaxation within the dot. It appears likely that this is due to straininduced interdiffusion of the silicon atoms into dots. The Raman data obtained for large dots formed at high growth temperatures agree with a model of $\mathrm{Ge} / \mathrm{Si}$ dots consisting of a Si-rich boundary region and a Ge-rich core. These conclusions, however, are based on indirect evidence since only average Ge content and strain but not their detailed profile within the dots can be obtained by micro-Raman spectroscopy, which possesses a low spatial resolution relative to the dot sizes investigated. However, this limitation could be overcome by using tip-enhanced Raman spectroscopy, ${ }^{32}$ a very promising technique for the investigation of the intermixing and strain profiles within $\mathrm{Ge} / \mathrm{Si}$ dots with nanoscale spatial resolution.

\section{ACKNOWLEDGMENTS}

Financial support from HEA and DIT (ICAS research grant, 2004), Ireland, are gratefully acknowledged. A.V.B. and A.V.F. thank the RFBR (Grant No. 05-02-16212) and the Russian Federal Agency of Science and Innovations (Project No. 2005-IN-13.1/004) for partial financial support during this work.
*Author for correspondence. FAX: +353 1 6772442. Electronic address: perovat@tcd.ie

${ }^{1}$ D. Bimberg, M. Grundmann, and N. N. Ledentsov, Quantum Dot Heterostructures (Wiley, Chichester, 1999).

${ }^{2}$ V. Le Thanh, Surf. Sci. 492, 255 (2001).

${ }^{3}$ K. Brunner, Prog. Theor. Phys. 65, 27 (2002).

${ }^{4}$ V. Baranov, A. V. Fedorov, T. S. Perova, R. A. Moore, S. Solosin, V. Yam, D. Bouchier, and V. Le Thanh, J. Appl. Phys. 96, 2857 (2004).

${ }^{5}$ K. Watanabe, N. Koguchi, and Y. Gotoh, Jpn. J. Appl. Phys., Part 2 39, L79 (2000).

${ }^{6}$ G. Hadjisavvas, P. Sonnet, and P. C. Kelires, Phys. Rev. B 67, 241302(R) (2003).

${ }^{7}$ U. Denker, M. Stoffel, and O. G. Schmidt, Phys. Rev. Lett. 90, 196102 (2003); U. Denker, A. Rastelli, M. Stoffel, J. Tersoff, G. Katsaros, G. Costantini, K. Kern, N. Y. Jin-Phillipp, D. E. Jesson, and O. G. Schmidt, ibid. 94, 216103 (2005).

${ }^{8}$ A. Hesse, J. Stangl, V. Holý, T. Roch, G. Bauer, O. G. Schmidt, U. Denker, and B. Struth, Phys. Rev. B 66, 085321 (2002).

${ }^{9}$ T. U. Schülli, M. Stoffel, A. Hesse, J. Stangl, R. T. Lechner, E. Wintersberger, M. Sztucki, T. H. Metzger, O. G. Schmidt, and G. Bauer, Phys. Rev. B 71, 035326 (2005).

${ }^{10}$ O. G. Schmidt, U. Denker, S. Christiansen, and F. Ernst, Appl. Phys. Lett. 81, 2614 (2002).

${ }^{11}$ J. Stangl, A. Hesse, V. Holý, Z. Zhong, G. Bauer, U. Denker, and O. G. Schmidt, Appl. Phys. Lett. 82, 2251 (2003).

${ }^{12}$ M. Stoffel, U. Denker, G. S. Kar, H. Sigg, and O. G. Schmidt, Appl. Phys. Lett. 83, 2910 (2003).

${ }^{13}$ B. Dietrich, E. Bugiel, J. Klatt, G. Lippert, T. Morgenstern, H. J. Osten, and P. Zaumseil, J. Appl. Phys. 74, 3177 (1993).

${ }^{14}$ Z. M. Jiang, C. W. Pei, X. F. Zhou, W. R. Jiang, B. Shi, X. H. Liu, X. Wang, Q. J. Jia, W. L. Zheng, and X. M. Jiang, Appl. Phys. Lett. 75, 370 (1999).

${ }^{15}$ S. H. Kwok, P. Y. Yu, C. H. Tung, Y. H. Zhang, M. F. Li, C. S. Peng, and J. M. Zhou, Phys. Rev. B 59, 4980 (1999).
${ }^{16}$ A. V. Kolobov and K. Tanaka, Appl. Phys. Lett. 75, 3572 (1999).

${ }^{17}$ J. L. Liu, Y. S. Tang, and K. L. Wang, Appl. Phys. Lett. 75, 3574 (1999).

${ }^{18}$ A. V. Kolobov, J. Appl. Phys. 87, 2926 (2000).

${ }^{19}$ P. H. Tan, K. Brunner, D. Bougeard, and G. Abstreiter, Phys. Rev. B 68, 125302 (2003).

${ }^{20}$ P. H. Tan, D. Bougeard, G. Abstreiter, and K. Brunner, Appl. Phys. Lett. 84, 2632 (2004).

${ }^{21}$ K. L. Teo, L. Qin, I. M. Noordin, G. Karunasiri, Z. X. Shen, O. G. Schmidt, K. Eberl, and H. J. Queisser, Phys. Rev. B 63, 121306 (2001).

${ }^{22}$ A. G. Milekhin, A. I. Nikiforov, M. Yu. Ladanov, O. P. Pchelyakov, D. N. Lobanov, A. V. Novikov, Z. F. Krasil'nik, S. Schulze, and D. R. T. Zahn, Physica E (Amsterdam) 21, 464 (2004).

${ }^{23}$ V. Le Thanh, V. Yam, P. Boucaud, F. Fortuna, C. Ulysse, D. Bouchier, L. Vervoort, and J.-M. Lourtioz, Phys. Rev. B 60, 5851 (1999).

${ }^{24}$ V. Le Thanh, in Physics, Chemistry and Application of Nanostructures, edited by V. E. Borisenko, S. V. Gaponenko, and V. S. Gurin (World Scientific, Singapore, 2003), p. 447.

${ }^{25}$ M. I. Alonso and K. Winer, Phys. Rev. B 39, 10056 (1989).

${ }^{26}$ J. C. Tsang, P. M. Mooney, F. Dacol, and J. O. Chu, J. Appl. Phys. 75, 8098 (1994).

${ }^{27}$ D. Olego and M. Cardona, Phys. Rev. B 25, 1151 (1982).

${ }^{28}$ O. G. Schmidt and K. Eberl, Phys. Rev. B 61, 13721 (2000); O. G. Schmidt, K. Eberl, and Y. Rau, ibid. 62, 16715 (2000).

${ }^{29}$ C. E. Bottani, C. Mantini, P. Milani, M. Manfredini, A. Stella, P. Toghini, P. Cheyssac, and R. Kofman, Appl. Phys. Lett. 69, 2409 (1996).

${ }^{30}$ S. Kanakaraju, A. K. Sood, and S. Mohan, J. Appl. Phys. 84, 5756 (1998).

${ }^{31}$ R. Schorer, G. Abstreiter, S. de Gironcoli, E. Molinari, H. Kibbel, and H. Presting, Phys. Rev. B 49, 5406 (1994).

${ }^{32}$ N. Hayazawa, M. Motohashi, Y. Saito, and S. Kawata, Appl. Phys. Lett. 86, 263114 (2005). 